\title{
Participação da família no desenvolvimento da aprendizagem da criança
}

\author{
Izabel Lúcia dos Santos Oliveira ${ }^{1}$, Andrelina Pelaes Braga ${ }^{2}$ e \\ Cleidia Maria Nogueira Prado ${ }^{3}$
}

\begin{abstract}
1 Mestra em Ciências da Educação pela Universidade de Évora, Especialização em Gestão e Docência do Ensino Superior, PósGraduada em Metodologia da Educação Especial pela Universidade do Estado do Pará e Licenciada em Pedagogia pela Universidade Federal do Pará. Professora da Secretaria de Educação do Amapá, Coordenadora Pedagógica da Secretaria Municipal do Amapá e Professora no Curso de Pós-Graduação na Faculdade de Teologia e Ciências Humanas, Brasil. E-mail: izabel_lucia@hotmail.com

2 Pós-Graduanda em Gestão, Supervisão e Orientação Educacional pela Faculdade de Teologia e Ciências Humanas e Licenciada em Pedagogia pela Universidade Vale do Acaraú, Brasil. E-mail: andreiabraga-ap@hotmail.com

3 Pós-Graduanda em Gestão, Supervisão e Orientação Educacional pela Faculdade de Teologia e Ciências Humanas e Licenciada em Pedagogia pela Universidade Vale do Acaraú, Brasil. E-mail: cleidiaprado@gmail.com
\end{abstract}

RESUMO: O Artigo objetivou analisar a importância da participação da família no desenvolvimento da aprendizagem da criança, por ser atualmente um grande problema enfrentado no contexto familiar, escolar e na atuação do professor, gestor escolar, coordenação escolar. Utilizou-se a abordagem qualitativa para subsidiar a pesquisa bibliográfica que fundamentou a construção do entendimento, análise e discussão do objeto de estudo. Os resultados apontam para uma certa lacuna na participação ativa da família no processo de ensino-aprendizagem da criança e consequentemente no acompanhamento dos filhos na escola. Enfim, é necessário que a família reconheça que é à base da sociedade e que constitui referenciais fundamentais para a construção de conhecimentos e formação social, cultural, moral, ética, religiosa, afetiva e principalmente escolar da criança.

Palavras-chave: Família. Escola. Participação. Ensino. Aprendizagem.

Family participation in child learning development

ABSTRACT: The article aimed to analyze the importance of family participation in the development of children's learning, as it is currently a major problem faced in the family context, school and in the work of the teacher, school manager, school coordination. The qualitative approach was used to support the bibliographic research that based the construction of the understanding, analysis and discussion of the object of study. The results point to a certain gap in the active participation of the family in the teaching-learning process of the child and consequently in the accompaniment of the children in the school. Finally, it is necessary for the family to recognize that it is the basis of society and that it constitutes fundamental references for the construction of knowledge and social, cultural, moral, ethical, religious, affective and especially school education of the child.

KEYWORDS: Family. School. Participation. Teaching. Learning.

\section{INTRODUÇÃO}

Este artigo tem como tema "Participação da família no desenvolvimento da aprendizagem das crianças", havendo a necessidade de preservar e reconstruir a relação da família com o contexto escolar, por ser de suma importância no processo de aprendizagem.

São nestes dois ambientes, mais especificamente no familiar, que a criança começa a desenvolver suas potencialidades e sua afetividade, complementando seu desenvolvimento no ambiente escolar onde irá 
aprender a conviver com o outro, desenvolvendo muitas outras capacidades que permitirão com que a criança tenha um desenvolvimento cognitivo. Partindo do pressuposto de que a educação é um processo contínuo e que se desenvolve no ambiente escolar, familiar e no convívio social, o presente trabalho objetivou analisar a importante da participação da família no desenvolvimento da aprendizagem do aluno.

A pesquisa fundamentou-se na abordagem qualitativa que subsidiou a pesquisa bibliográfica baseada nas ideias de alguns autores, que contribuíram significativamente com o desenvolvimento do trabalho, sendo eles: Prado, López, Witter, entre outros que abordam com relevância o referido tema.

Assim, a realização desta pesquisa é relevante na medida em que reafirmar a importância do envolvimento e comparecimento constantes da família no espaço escolar, sendo uma relação de inteira sintonia e compartilhando um mesmo ideal para superação dos conflitos e dificuldade que tanto preocupa os professores, pais e os próprios alunos, resultando em uma interação de confiança, acolhida e cumplicidade. Logo, família e escola acabam assumindo as responsabilidades que Ihe são cabíveis, tendo em vista, que família e escola são instituições complementares no processo de educação e formação do indivíduo.

\section{A CONTRIBUIÇÃO DA FAMÍLIA NO DE- SENVOLVIMENTO DA APRENDIZAGEM}

A sociedade brasileira vem passando por grandes transformações no campo socioeconômico, cultural e político, que refletem diretamente nos grupos sociais que a compõe, que sofrem transformações no modo de vida e estrutura organizacional. Entre tais grupos está à instituição familiar que busca manter-se viva em meio a tantas mudanças pelas quais teve que se adequar, desempenhando não somente a função de perpetuar a espécie, mas também de cuidar para que seus membros se desenvolvam plenamente.

Ressalta-se que o conceito de família foi se modificando ao longo da história da humanidade, onde cada sociedade tem sua concepção de família. Assim sendo, o seu conceito passou a ser definido de várias maneiras, assumindo as características de cada povo e região, e consequentemente adquirindo um significado muito amplo. Segundo o Dicionário Aurélio Buarque (2001, p.31), a palavra família "significa pessoas aparentadas que vivem na mesma casa, particularmente o pai, a mãe e os fiIhos, pessoas do mesmo sangue, origem, ascendência", sendo este o conceito mais tradicional disseminado e frequente nos setores da sociedade brasileira, que serve de paradigma para organização social, educacional e religioso.

No começo do século XX foi possível observar algumas mudanças, na estrutura familiar definida como conjunto de pessoas aparentadas que viviam na mesma casa, sendo pai, mãe e filhos e que constituíam uma família nuclear, muda de configuração (PRADO, 2011). Esta mudança conceitual foi instituída na Constituição de 1988, que passou a considerar uma nova estrutura familiar, ao reconhecer a união estável como célula familiar.

Atualmente, é possível reconhecer uma mãe com filhos, sem designação de um pai como uma instituição familiar, assim, a família não é um simples fenômeno natural, ela é "uma instituição social que varia ao 
longo da história e até apresenta formas e finalidades diversas numa mesma época e lugar, conforme o grupo social que esteja sendo observado" (PRADO, 2011, p. 17). Com isto, observa-se que apesar das mudanças sobre o conceito de família no contexto histórico, a mesma ainda está ligada a laços matrimoniais, sanguíneos e a descendência.

Constata-se nos dias contemporâneas, que não existe uma configuração familiar ideal e padronizada, porque são inúmeras as combinações e formas de interação entre os indivíduos que constituem os diferentes tipos de famílias, podendo denominá-las como nuclear tradicional, recasadas, monoparentais, homossexuais, dentre outras combinações. Os padrões familiares vão se transformando e se adequando as atuais realidades e necessidades da humanidade, tornando-se difícil distinguir as características do grupo familiar contemporâneo. Assim, o conceituar a instituição familiar tornou-se difícil, pois esta atualmente apresenta modelos e conceito indefinido (PRADO, 2011).

Nesse sentido acredita-se, que a família desempenha importante papel no desenvolvimento dos filhos, pois, é no convívio desta, que eles encontram todos os elementos necessários, como afetividade, confiança, motivação, autonomia, e respeito, colocando-a na condição de alicerce para o desenvolvimento humano e da aprendizagem, tendo em vista que é a família quem possibilita as primeiras aprendizagens dos filhos (PRADO, 2011).

A família não pode ignorar suas funções e responsabilidades em relação a seus membros, principalmente quando nos primeiros anos de vida, pois é nesta fase que a criança estabelece as bases para o desen- volvimento de sua personalidade, caráter e afetividade (WITTER, 2011). Os pais por sua vez, são os responsáveis diretos na formação social dos seus filhos, de modo que todas as suas atitudes são absorvidas com naturalidade por parte das crianças, já que é no

convívio familiar que a criança não só aprende a resolver os conflitos, como também a administrar as questões emocionais e os diferentes e diversos sentimentos das relações pessoais e interpessoais, e ainda a enfrentar as adversidades que a vida pode apresentar, pois essas redes de interações incluem fatores emocionais, sociais, afetivos e culturais. (WITTER, 2011, p. 34)

Portanto, os laços sociais, afetivos e culturais que a criança constrói no seio familiar ou meio em que se encontram inseridos irão fortalecê-lo como pessoa e ajudá-lo a resolver conflitos, a conviver e se adaptar a diferentes ambientes e situações que possam vivenciar no decorrer de sua vida.

É por meio das interações familiares e sociais que a criança desenvolve sua autoestima, constrói sua identidade e conhecimentos que irão norteá-la na maior parte de sua vida. No meio familiar o indivíduo irá buscar energia, sustentação para enfrentar situações difíceis de serem vivenciadas (PORTES, 2000). Nesse sentido, pode-se afirmar que não há uma instituição que possa vir substituir a família e propiciar ao individuo os subsídios necessários para o seu pleno desenvolvimento social, cultural, afetivo e pessoal, mais sim para complementá-lo.

A família é a peça principal para o desenvolvimento da aprendizagem, pois favorece a base estrutural necessária e sólida para construção de valores, do desenvolvimento 
emocional, social e da expressão oral, e esses são "aspectos do desenvolvimento pessoal que podem ser maiores ou menores em decorrência de todo o contexto físico, social, psicológico e ético que o lar oferece à criança" (WITTER, 2011, p.46). Desta forma, todas as experiências vivenciadas na convivência familiar servirão de pressupostos para o desenvolvimento da aprendizagem escolar, bem como para o convívio em sociedade por toda a existência do indivíduo.

É valido ressaltar que, em qualquer formação familiar, são os pais as principais referências na vida dos filhos, pois servem de modelo para a construção da personalidade e do comportamento da criança, bem como influenciam na construção e legitimação dos valores morais, éticos, religiosos e sociais (WITTER, 2011). Assim, a participação dos pais deve ocorrer com frequência no contexto escolar, pois é através desse contato que a família poderá observar e auxiliar no desenvolvimento da criança.

Assim, a família e a escola precisam construir e consolidar esse relacionamento, buscando junta resgatar os valores, contribuindo assim, para a construção da identidade da criança, estimulando sua autonomia. Ambas fazem parte do processo educativo da mesma, já que "a eficácia da educação escolar depende do grau de implicação, enfim do grau de participação dos pais" (LÓPEZ, 2002, p.82), os quais influenciam positivamente no desenvolvimento da aprendizagem.

Atualmente é possível perceber o descaso, de algumas famílias, com a educação dos seus filhos, por serem ausentes e não acompanharem ativamente das atividades escolares, por se omitirem e tentar repassar à escola suas responsabilidades. E esta situ- ação implica de forma negativa no desenvolvimento da aprendizagem da criança, já que a sua educação fica por conta da escola, que não consegue desempenhar tal função a contento.

Isso ocorre na medida em que existem outros fatores, que de alguma forma acabam influenciando na aprendizagem da criança, de forma negativa ou positiva, como a televisão que está presente em todos os lares, e muitas vezes é a principal companheira da criança (LÓPEZ, 2002).

Assim, a falta de convivência diária da família com aa crianças dificulta a transmissão de valores morais e éticos, além de imporem limites e atos disciplinares aos filhos. E esta falta de participação dos pais na vida dos filhos, algumas vezes, acontece em decorrência da carga elevada de trabalho (WITTER, 2011).

Porém, quando a família atua em parceria com a escola a aprendizagem flui com mais amplitude, a criança sente-se estimulada e consegue assimilar os conhecimentos com facilidade, pois a família acaba reforçando e contribuindo para a consolidação dessa aprendizagem. A criança precisa perceber que o que lhe é ensinado na escola, é validado pela família e que família e escola se ajudam mutuamente em prol do mesmo objetivo, a eficácia do processo de ensino aprendizagem (WITTER, 2011).

\section{FAMÍLIA E ESCOLA: PARCERIAS NECES- SÁRIAS PARA O DESENVOLVIMENTO DA APRENDIZAGEM}

Entende-se que a família é uma instituição presente na sociedade capaz de transmitir conhecimentos, crenças e valores a seus membros de forma que tais informações vão legitimando-se naturalmente. Po- 
rém, tal instituição não é a única com a responsabilidade de difundir conhecimentos, pois em meio à sociedade encontra-se atrelada à ela a instituição escolar, que também desempenha importante papel nesse processo, sendo que ambas compartilham de funções sociais, políticas e educacionais, à medida que atuam na transmissão e construção de conhecimentos (WITTER, 2011).

Por muito tempo, a família foi a única e principal responsável pela educação de seus filhos. Mas a partir da idade média começaram a ocorrer mudanças nesse aspecto e a educação sistematizada passou a ser produto da escola. Assim, surgiram profissionais formados e especializados na transmissão de conhecimentos e ambientes específicos para o desenvolvimento da atividade escolar. Porém, o acesso à educação escolar era elitizado, o que a tornava um instrumento de separação das classes sociais (ROMANELLI, 2009).

De acordo com Romanelli (2009, p. 24), "a função [da escola] desta foi a de manter privilégios, pois a própria instituição se apresenta como privilégio da classe dominante a partir do momento que se utiliza de mecanismos seletivos e de conteúdo cultural", e a escola apresenta-se como uma instituição especializada que atendia aos filhos das famílias de poder na sociedade.

A partir do século XIX, com o desenvolvimento da industrialização, a escola passou por grandes transformações, pois as pessoas começaram a desenvolver o trabalho nas fábricas e a passarem mais tempo fora de casa. Com isso a família sofreu mudanças, já que sozinha não conseguia mais educar seus filhos para o trabalho e para a vida social, passando a dividir com a escola tal responsabilidade. As classes trabalhadoras se fortaleceram e passaram a exigir o acesso de seus filhos à escola, que foi obrigada a abrir suas portas, passando a atender às camadas sociais menos favorecidas (ROMANELLI, 2009).

Atualmente, a escola apresenta-se como uma das mais importantes instituições sociais, pois exerce a função de mediadora do conhecimento entre o indivíduo e a sociedade, transmitindo modelos sociais de comportamento, valores morais, éticos e culturais; além de contribuir no desenvolvimento da aprendizagem, na convivência com outros grupos sociais. A ação educativa da escola favorece a sistematização do conhecimento e também colaborar que a criança aos poucos vá deixando de imitar o comportamento dos pais e familiares, que eram suas únicas referências até o momento, adquirindo assim, sua autonomia e desenvolvendo sua consciência de pertencimento a outros grupos sociais (PORTELA; FRANCESCHINI, 2008).

Salienta-se que a escola surgiu para responder às necessidades de preparo do indivíduo, sendo responsável pela transmissão de conhecimentos curriculares organizados de modo sistemático, que irão subsidiá-lo em seu desenvolvimento social, cognitivo e profissional, deixando para a família a formação moral, social e afetiva dos filhos, ou seja, condições básicas de convivência em sociedade. (PORTELA; FRANCESCHINI, 2008).

Cabe à família o papel de transmitir e aprimorar novos conhecimentos e valores, que serão fundamentais para o convívio social. Desta forma, "a família e a escola compartilham funções educacionais políticas e sociais, pois ambas integram o quadro de formação do cidadão" (WINTTER 2011, p. 50) desempenham um importante papel no desenvolvimento da aprendizagem. 
Portanto, a família, devendo incumbir-se da transmissão de valores morais, hábitos e comportamentos, tais fatores ou atos, nem sempre "conscientemente intencionais, não institucionais, não planejados, envolvem tudo que impregna a vida social, como o ambiente e as relações socioculturais, e atuam na formação das pessoas" (LIBÂNEO; OLIVEIRA; TOSCHI, 2005, p.169). Portanto, a família atua no desenvolvimento da aprendizagem de forma assistemática, através das relações e influências do meio natural e social.

A Lei 9394/96, amplia o conceito de educação ao assegurar que o processo educacional não se dá apenas no âmbito escolar, mas se constitui em todo e qualquer lugar (BRASIL, 1996). Abrangendo também os processos formativos que se desenvolvem na vida familiar, na convivência humana, no trabalho, nas instituições de ensino e pesquisa, nos movimentos sociais e organizações da sociedade civil e nas manifestações culturais (BRASIL, 1996).

Ainda no art. 2을 da Lei de Diretrizes e Bases da Educação (9394/96), amplia e divide a responsabilidade da família para com a educação, onde ressalta a importância do convívio familiar para a formação do comportamento humano, assim como para o desempenho de suas capacidades intelectuais (BRASIL, 1996).

Portanto, os conhecimentos adquiridos no seio familiar irão assegurar o desenvolvimento pleno e saudável das funções mentais da criança, pois é na família que ela desenvolve sua estrutura emocional, e outras como, maturidade, respeito, autoestima e afetividade, fatores psicossociais que irão acompanhá-la ao longo de sua vida e servirão de base de sustentação para o desenvolvimento da aprendizagem (BRASIL,
1996).

É importante ressaltar que a escola e família são instituições que atuam diretamente no desenvolvimento da aprendizagem, são as duas principais instituições presentes na sociedade responsáveis pela transmissão e construção de conhecimentos, portanto "é imprescindível que família e escola unam esforços e estratégias em busca de objetivos comuns, desenvolvendo, cada uma, seu papel e ao mesmo tempo juntas na função de educar, pois nenhuma pode assumir a responsabilidade da outra" (ROMANELLI, 2009, p. 26)

A obrigatoriedade da família em acompanhar o processo de escolaridade dos fiIhos e a sua presença no contexto escolar é reconhecido publicamente e assegurado pela legislação federal e educacional vigente no país, segundo a Constituição Federal (1988) em seu art. 227 é dever da família, da sociedade e do Estado assegurar à criança e ao adolescente, com absoluta prioridade, o direito vida, saúde, alimentação e educação (BRASIL, 1988), cabendo à família zelar pelo desenvolvimento das crianças, oferecendo um ambiente propício e harmonioso e de integração com a escola, para que ela possa se desenvolver em ambos os ambientes.

A família precisa manter um relacionamento estreito com o ambiente escolar, pois somente assim poderá fazer um "acompanhamento amplo do desenvolvimento da criança, de suas aprendizagens e dificuldades, compreendendo que a escola é o lugar onde irá aprender a conviver, é, portanto, o lugar oportuno para desenvolver os hábitos de socialização que a vida em comunidade requer" (LÓPEZ, 2002, p.23), fazendo-se necessária a intervenção da família para que esse processo de adaptação e 
desenvolvimento cognitivo seja o melhor possível.

\section{CAMINHOS METODOLOGICOS E DISCUS- SÃO DOS RESULTADOS}

A pesquisa sobre o tema "Participação da família no desenvolvimento da aprendizagem da criança" surgiu da necessidade de compreensão e análise sobre a importância do envolvimento, comparecimento e intervenção constantes da família no espaço escolar, visando a resolução da problemática do desenvolvimento da qualidade da aprendizagem da criança.

E para que estes propósitos fossem alcançados realizou-se a pesquisa através de uma abordagem qualitativa, analisar o objeto estudado pela sua descrição e interpretação, com o desejo de conhecer alguns eixos norteadores que respaldam uma relação de inteira sintonia e compartilhando um mesmo ideal para superação dos conflitos e dificuldade que tanto preocupa os professores, pais e os próprios alunos.

Ressalta-se que Chizzotti (2008) coloca que a pesquisa qualitativa parte do fundamento de que há uma reflexão dinâmica entre o mundo real e o sujeito, uma interdependência viva entre o objeto e sujeito, um vínculo indissociável entre o mundo objeto e a subjetividade do sujeito.

Neste estudo, a abordagem qualitativa subsidiou a realização da pesquisa bibliográfica que fez um apanhado das principais literaturas pertinentes ao tema, visto que esta pesquisa se caracteriza por ser a pesquisa com uso de material já elaborado e publicado e sua finalidade é colocar o pesquisador em contato direto com tudo o que foi escrito sobre determinado assunto (MARCONI; LAKATOS, 2008, p. 43). Assim, o pesquisador amplia seus conhecimentos através da leitura de obras publicadas por autores fluentes no assunto, como: Prado (2011), Romanelli (2009), Lopez (2002), Witter (2011) e outros para fundamentar e validar o processo de análise, discussão e construção dos resultados.

A fim de traçar um apanhado bibliográfico da temática estudada foram consultadas obras literárias na biblioteca da FATECH, nos bancos de dados das pós-graduações da Universidade Federal do Amapá, nos acervos digitais disponibilizados no Google Acadêmico <scholar.google.com.br> e no Coordenação de Aperfeiçoamento de Pessoal de Nível Superior (CAPES), sendo pesquisado sobre o título de "a importância da família no desenvolvimento da aprendizagem escolar".

\subsection{Discussão dos resultados}

Não se pode negar que a parceria entre as duas principais instituições sociais, escola e família, é de suma importância para o desenvolvimento da aprendizagem da criança. Logo, devem associar responsabilidades, esforços e estratégias no desenvolvendo de seus filhos. Mas juntas na função de educar as crianças, sem assumirem a responsabilidade da outra. (ROMANELLI, 2009).

Para este estudo, buscamos responder a seguinte problemática: é relevante a participação da família no desenvolvimento da aprendizagem da criança? E neste intuito, a pesquisa bibliográfica revelou algumas considerações referentes ao questionamento, que destacamos abaixo:

1. Sobre a importância da participação da família no desenvolvimento da aprendizagem das crianças: é na família que a criança adquire a base da formação moral, ética, 
social, religiosa, cultural e escolar que contribui na formação da personalidade, caráter e conduta. A família deve ser parceira da escola, que dá continuidade a aprendizagem da criança, pois a escola não trabaIha sozinha e a família faz parte da formação educacional de suas crianças, e deve participar ativamente da vida escolar dos filhos.

Portanto, é muito importante a participação ativa da família no processo de ensino-aprendizagem da criança, pois é a família quem dá inicio ao processo da construção do conhecimento, através da construção de valores, do desenvolvimento emocional e social. Caso não se concretizar tal "participação da família na escola, não se pode alcançar uma educação coordenada e eficaz dos filhos" (LÓPEZ, 2002, p.84). Desde cedo as crianças e a própria família, precisam perceber a importância da educação em suas vidas e isso só é possível se os pais participarem ativamente desse processo.

Assim, a própria família deve reconhece a sua importância na participação ativa no processo de ensino de seus filhos, buscando alternativas e brechas em seu horário de trabalho para visitar a instituição escolar para realizar o acompanhamento frequente do calendário escolar. Pois se "deve reconhecer que as condições de famílias trabaIhadoras dificultam um acompanhamento mais próximo do trabalho acadêmico das crianças" (WITTER, 2001, p. 68). No entanto, apesar das diversas funções desempenhadas na vida profissional, as famílias não podem se omitir em desempenhar seu papel de ter, criar, proteger e educar os filhos.

É fundamental que a família esteja engajada no processo de aprendizagem da criança, tendo um papel ativo na educação escolar, pois os pais "não podem abdicar de sua responsabilidade de educadores, e representam a sociedade receptora da atuação das escolas" (LÓPEZ, 2002, p.78). Devendo os pais participarem com frequência das atividades proporcionadas pela escola, passarão a conhecer o trabalho desenvolvido, de que forma a criança esta aprendendo e suas dificuldades.

Destacamos que o acompanhamento da família no processo de escolaridade dos filhos e seu comparecimento no contexto escolar são reconhecidos e assegurados pela legislação federal e educacional vigente no país, Lei no 9394/96, bem como a Constituição Federal (1988) em seu art. 227 dispõe que é dever da família, da sociedade e do Estado assegurar à criança e ao adolescente, com absoluta prioridade, o direito à vida, à saúde, à alimentação, à educação. (BRASIL, 1988), cabendo à família zelar pelo desenvolvimento das crianças, oferecendo um ambiente propício e harmonioso e de integração com a escola, para que ela possa se desenvolver plenamente e com segurança, em ambos os ambientes.

2.Os alunos recebem acompanhamento da família no desenvolvimento de suas aprendizagens: não se pode afirmar com exatidão que a família de modo geral não faz o acompanhamento de seus filhos na escola, porém uma boa parte das crianças deixa de realizar suas tarefas, até mesmo de deixam de frequentarem a escola por falta de um acompanhamento familiar ativo e continuo, ou abandono completo.

É possível perceber que alguns pais ainda não compreendem o quanto a sua participação na educação da criança é relevante, e sem a menor responsabilidade ou algumas vezes involuntariamente, por falta de conhecimento, acabam se omitindo nesse 
processo. Ao demonstrarem descaso com o ensino escolar destes, acabam prejudicando o desenvolvimento de suas aprendizagens, tornando-as desmotivadas para realizar tarefas escolares e até mesmo frequentar a escola, pode-se dizer que "a perda da oportunidade educacional dos primeiros anos é irrecuperável, pois nesse período se adquirem traços que marcam os aprendizados e a vida posterior" (LÓPEZ, 2002, p.25), um a criança sem estímulos para estudar, tornase um adulto desmotivado e com possíveis déficits de aprendizagem.

Para que ocorra uma aprendizagem significativa e eficaz é necessário o interesse da família em participar da construção desta aprendizagem, "buscando sempre o desenvolvimento dos filhos a família atual é o esteio na formação da criança e do adolescente, há muitas variáveis no ambiente familiar que são importantes. Algumas variáveis podem por em risco, prejudicar ou mesmo impedir o desenvolvimento dos filhos" (WITTER, 2011, p.44).

Uma família atuante na vida escolar dos filhos pode contribuir significativamente com o aprendizado destes, através da participação nas atividades desenvolvidas e estímulos necessários para a execução das mesmas, por outro lado, se não participar e estimular as crianças, estas podem sentir-se desmotivadas e vulneráveis a apresentar dificuldades no seu desenvolvimento intelectual.

A escola precisa investir sempre na participação da família no contexto escolar e na aprendizagem dos filhos, de forma a beneficiar o processo de ensino aprendizagem, não apenas nos momentos em que as crianças apresentarem dificuldades ou o professor chamar. As crianças que recebem acompanhamento efetivo apresentam um melhor rendimento e isso possibilita evitar o possível fracasso escolar e auxilia significativamente no aprendizado da criança. (PRADO, 2011)

Os pais precisam estar em contato com a instituição escolar, procurando obter informações sobre os avanços e dificuldades de suas crianças e oferecer suporte para superar eventuais obstáculos. Assim, a família não deve encontrar na escola uma concepção de educação oposta à sua, mas sim de modo a complementá-la, de forma que a relação entre essas duas instituições possa contribuir significativamente com a promoção da aprendizagem das crianças. (PRADO, 2011)

A família precisa fazer-se presente na vida dos filhos e principalmente nos anos iniciais de escolarização, que é quando estes começam a legitimar os valores adquiridos no ambiente familiar, enquanto o contato entre família e escola é necessário em qualquer idade, durante os primeiros anos ele terá de ser mais intenso para coordenar as atividades educativas que permitam a rápida aquisição dos hábitos propostos. (LÓPEZ, 2002, p.27), dessa forma a escola fica limitada com seus objetivos, e não pode conduzirsozinha o processo de desenvolvimento da aprendizagem da criança de forma ampla, é preciso que haja uma cooperação entre família e escola.

Desta forma, não cabe a escola desempenhar em sua totalidade funções que também são da família. O papel da escola vai além da transmissão de conteúdos e conhecimentos, já que é no ambiente escolar que o sujeito adquire uma ampla especificidade de conhecimentos e aperfeiçoa seu aprendizado de viver em sociedade (ROMANELLI, 2009)

Através da análise realizada mediante a 
pesquisa bibliográfica, pode-se observar que algumas famílias não possuem consciência de que são os principais responsáveis pelos filhos e pela sua educação, e do quanto podem contribuir na aprendizagem destes. E se omitir deste processo é passar a responsabilidade de educar para a escola, que por sua vez não está conseguindo desempenhar por completo tal função. A família nunca pode renunciar a sua responsabilidade educacional, principalmente durante os primeiros anos da vida infantil, exatamente quando se estabelece as bases da futura personalidade da criança. (LOPÉZ, 2002, p.28), uma criança bem assistida pela família torna-se um adulto saudável e confiante em suas atitudes e em si mesmo.

\section{CONSIDERAÇÕES FINAIS}

Tendo em vista o estudo do levantamento bibliográfico, pode-se afirmar que a família vem sofrendo inúmeras mudanças durante os séculos de existência, em suas conjunturas, como também em suas responsabilidades. Por muito tempo a família foi constituída por pai, mãe e filhos, denominada de família nuclear, e se apresentava para a criança como primeiro ambiente de socialização e transmissora de valores e comportamentos, hoje não existe um modelo familiar definido, porém ainda é a principal formadora de conhecimentos e valores que irão subsidiar o desenvolvimento dos filhos e sua convivência na sociedade.

É valido salientar o papel da mulher na estrutura familiar, pois as mulheres que antes se ocupavam apenas da casa e da educação dos filhos, hoje dividem espaço no mercado de trabalho com os homens, e isto Ihe obriga a se ausentar por longas horas do convívio familiar e consequentemente da educação dos filhos.

Assim, as famílias atuais apresentam certas dificuldades para oferecer todo o suporte que a criança precisa para seu desenvolvimento integral, educação, carinho e atenção, porém é válido ressaltar que a família é à base de todo o aprendizado e desenvolvimento do individuo, e esta não pode se negar a cumprir sua função, pois nenhuma outra instituição poderá oferecer a criança tais insumos necessários para o seu desenvolvimento. É no ambiente familiar que se concretizam os primeiros contatos com o mundo externo e com a linguagem, ocorrem as primeiras aprendizagens da criança no que se refere a valores e hábitos repassados através dos adultos ali presentes e que irão refletir por toda a sua vida pessoal e em sociedade.

Constatou-se, que é possível se ver no espaço escolar que faltam esforços por parte de algumas famílias para concretizar a relação e a parceria entre a escola e a família. E a escola ainda precisa continuar criando melhores estratégias de aproximação escola-família, de modo a responsabilizar a família e torná-la parte do processo educativo dos filhos, assim como, a família também precisa repensar sobre sua postura no processo escolar dos filhos.

Verificou-se ainda que hoje algumas famílias não estão fazendo o acompanhamento contínuo do desenvolvimento da aprendizagem dos filhos e não conseguem oferecer a atenção que estes necessitam para desenvolver habilidades e competências que irão acompanhá-lo por toda a sua vida pessoal e em sociedade. A família atual parece preocupar-se mais com sua vida profissional, passando a responsabilidade da educação dos filhos para a escola, com isso, 
muitas vezes expõem os filhos ao fracasso, pois sem o apoio dos pais, sentem-se desmotivados e reprimidos.

Observou-se também que as dificuldades vivenciadas por alguns pais em acompanhar o processo escolar dos seus filhos vêm refletindo na aprendizagem e no comportamento destes. Mas ainda assim é possível perceber que mesmo diante de tantos compromissos da sociedade moderna ainda existem famílias que disponibilizam tempo para auxiliar o aprendizado dos filhos no interior do lar, dividindo responsabilidades e tarefas com escola, estabelecendo uma relação de parceria ativa no processo de desenvolvimento da aprendizagem de seus filhos, bem como contribuindo significativamente no espaço escolar com ações coletivas e sociais.

Nesse sentido torna-se pertinente, sugerir que a escola busque desenvolver ações com intuito de sensibilizar os pais para a importância de sua participação no desenvolvimento da aprendizagem de seus filhos, pois, acredita-se que se os pais souberem do poder da influencia da sua participação ativa na vida de seus filhos, se forem orientados sobre a importância do estimulo precoce e das relações saudáveis em família.

É possível constatar, por meio da pesquisa bibliográfica, a grandiosa relevância da influencia da família no desenvolvimento da aprendizagem das crianças, a família é a base da sociedade. Portanto, as instituições família e escola constituem referenciais fundamentais para a construção de conhecimentos e formação social da criança, sendo que nenhuma destas pode eximir-se de suas responsabilidades para com a educação que virá refletir na formação de novas gerações e da sociedade.

\section{REFERÊNCIAS}

AURÉLIO, Aurélio Buarque. Dicionário da Língua Portuguesa. 4 ed. São Paulo: Nova Fronteira, 2001.

BRASIL, Constituição da Republica Federativa do Brasil. Brasília: Congresso Nacional, 1988.

. Lei de diretrizes e Bases da Educação Brasileira no 9394/96. Brasília: Ministério da Educação, 1998.

CHIZZOTTI, Antônio. Pesquisa em ciências humanas e sociais. São Paulo: Cortez, 2008. LAKATOS, Eva Maria, MARCONI, Marina de Andrade. Metodologia do trabalho científico: procedimentos básicos, pesquisa bibliográfica, projetos e relatórios, publicações e trabalhos científicos. São Paulo: Atlas, 2008. LIBÂNEO, José Carlos; OLIVEIRA, João Ferreira de; TOSCHI, Mirza Seabra. Educação escolar, políticas, estrutura e organização. 2a Ed. São Paulo: Cortez, 2005. (Coleção Docência e Formação).

LÓPEZ, Jaume Sarramona I. Educação na família e na escola: o que é e como se faz. São Paulo: Edições Loyola, 2002.

PRADO, Danda. O que é família. São Paulo: Brasiliense, 2011. Coleção Primeiros Passos. PORTELA, Fabiani Ortiz; FRANCESCHINI, Ingrid Schröeder. Família e aprendizagem: uma relação necessária. 2 ed. Rio de Janeiro, 2008.

PORTES, E.A. O trabalho escolar das famílias populares. In: NOGUEIRA, M.A; ROMANELLI, G. ZAGO, N. Família e escola: Trajetória da escolarização em camadas médias e populares. Petrópolis, RJ: Vozes, 2000.

ROMANELLI, Otaíza de Oliveira. História da educação no Brasil. 34 ed. Petrópolis: Vozes, 2009.

WITTER, Geraldina Porto. Família e aprendizagem. Cotia, SP: Ateliê Editorial, 2011. 


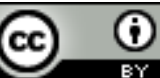

License information: This is an openaccess article distributed under the terms of the Creative Commons Attribution License, which permits unrestricted use, distribution, and reproduction in any medium, provided the original work is properly cited.

Artigo recebido em 28 de abril de 2016.

Avaliado em 08 de agosto de 2017.

Aceito em 31 de agosto de 2017.

Publicado em 22 de setembro de 2017.

\section{Como citar este artigo (ABNT):}

OLIVEIRA, Izabel Lúcia dos Santos; BRAGA, Andrelina Pelaes; PRADO, Cleidia Maria Nogueira. Participação da família no desenvolvimento da aprendizagem da criança. Estação Científica (UNIFAP), Macapá, v. 7, n. 2, p. 33-44, maio/ago. 2017. 